\title{
Sistem Cerdas Pemanggang Jagung Semi Otomatis Berbasis Mikrokontroler Menggunakan Metode PWM (Pulse Width Modulation
}

\author{
"Darjat Saripurna, *Ahmad Calam, , "* Yusnidah, "Zulkifli Lubis \\ *STMIK Triguna Dharma \\ **A Akademi Maritim Indonesia
}

\begin{tabular}{l}
\hline \hline Article Info \\
\hline Article history: \\
Received Okt 22, 2018 \\
Revised Jan 18, 2019 \\
Accepted Feb 07 ${ }^{\text {th }}, 2019$ \\
\end{tabular}

\section{Keyword:}

Pembakaran Jagung

Pulse Width Modulation

Mikrokontroler

Sensor LM35

\begin{abstract}
Proses pembakaran jagung yang dilakukan para pedagang saat ini dilakukan secara konvensional, pada saat pembalikan jagung dilakukan dengan manual dibalikkan dengan menggunakan tangan dan pada saat mengipas juga dilakukan dengan tangan sehingga cukup banuak tenaga yang dikeluarkan. Proses seperti ini mengakibatkan kematangan jagung tidak merata.

Dari hasil pengamatan inilah terbentuk suatu ide dimana pada saat proses pembakaran jagung dan pengipasan dilakukan secara otomatis. Dengan penambahan sensor LM35 sebagai pendeteksi suhu dan Motor DC sebagai pembalik/penggerak jagung yang dikendalikan oleh mikrokontroler serta implementasi teknik PWM (Pulse Width Modulation), digunakan untuk mengatur kecepatan putar alat pemanggang jagung.

Dengan solusi yang dirancang tersebut dapat membantu pembakaraan agar lebih rata, cepat dan lebih banyak jagung. Jika bara api menyala dengan baik, pemutaran/pembalikkan jagung akan berputar sesuai bara api, sehingga waktu yang dibutuhkan akan lebih cepat. Teknik yang digunakan membuat sistem tidak menghabiskan sumber daya yang cukup banyak.
\end{abstract}

Copyright (C) 2019 STMIK Triguna Dharma. All rights reserved.

\section{PENDAHULUAN}

Jagung adalah salah satu tanaman pangan penghasil karbohidrat yang terpenting di dunia, selain gandum dan padi. Hampir semua orang mengenal dan menyukai makanan yang berbahan dasar jagung, rasanya yang manis dengan tekstur yang lembut, pas di hampir semua lidah. Jagung juga memiliki banyak manfaat bagi kesehatan tubuh kita, yaitu : baik untuk pencernaan, mencegah anemia, sumber energi, menurunkan kolesterol, mencegah diabetes. Saat ini sudah banyak usaha yang berbahan dasar jagung, salah satunya usaha jagung bakar. Usaha jagung bakar merupakan salah satu usaha yang dapat kita lihat dimana saja dengan berbagai ragam rasa. Proses pembakaran jagung yang dilakukan para pedagang saat ini dilakukan secara konvensional dengan caranya pertama-tama, panaskan arang, kemudian pindahkan arang yang telah menjadi bara ke dalam pemanggangan, sementara itu siapkan jagung bakar yang telah dikupas, tusuk dengan tusukan dan letakkan di atas pembakaran. Peralatan pembakaran jagung masih dilakukan secara manual pada pengipasan bara/api dan pembalikan jagung. Sehingga proses dalam pembakaran jagung membutuhkan waktu yang lama dan tenaga yang berlebih. Dikarenakan waktu tersebut pembeli diharuskan menunggu lebih lama terlebih bila memesan dengan jumlah yang banyak. Didalam pengipasan dan pembalikan pada proses pembakaran jagung bakar masih menggunakan cara manual, artinya dengan tenaga manusia. Dan hasil pengamatan inilah terbentuk suatu ide dimana proses pembakaran jagung dengan secara otomatis sehingga dapat meningkatkan hasil penjualan yang maksimal dikarenakan sistem akan bekerja otomatis.

Dalam sistem pembakaran jagung ini menggunakan suatu metode, yaitu menggunakan metode PWM (Pulse Width Modulation). PWM (Pulse width Modulation) adalah salah satu teknik modulasi dengan mengubah lebar pulsa (duty cycle) dengan nilai amplitudo dan frekuensi yang tetap. Satu siklus pulsa merupakan 
kondisi high kemudian berada di zona transisi ke kondisi low. Lebar pulsa PWM berbanding lurus dengan amplitudo sinyal asli yang belum termodulasi. Duty Cycle merupakan representasi dari kondisi logika high dalam suatu periode sinyal dan di nyatakan dalam bentuk (\%) dengan range 0\% sampai 100\%. Metode ini digunakan untuk mengatur kecepatan serta ketepatan Motor DC dalam pembalikan jagung dan pengipasan

\section{LANDASAN TEORI}

\subsection{Jagung}

Jagung merupakan tanaman semusim (Annual Plants). Satu siklus hidupnya diselesaikan dalam $80-150$ hari. Paruh pertama dari siklus merupakan tahap pertumbuhan vegetatif, dan paruh kedua untuk tahap pertumbuhan generatif. Tinggi tanaman jagung sangat bervariasi. Meskipun tanaman jagung umumnya memiliki ketinggian antara 1 meter sampai 3 meter, namun ada varietas yang dapat mencapai tinggi 6 meter. Tinggi tanaman bisa diukur dari permukaan tanah hingga ruas teratas sebelum bunga jantan (Suprapto,2011). Jagung adalah termasuk tanaman monokotil (tumbuhan berbiji tunggal) sehingga perakarannya pun tergolong akar serabut yang kedalamannya dapat mencapai 8 meter, meskipun sebagian besar berada pada kisaran 2 meter. Batang tanaman jagung tegak dan mudah terlihat, seperti sorgum dan tebu (Suprapto,1995).

\subsection{Mikrokontroler}

Menurut Syahwil (2013:53) Mikrokontroler adalah sebuah sistem komputer fungsional dalam sebuah chip. Di dalamnya terkandung sebuah inti prosesor, memori (sejumlah kecil RAM, memori program atau keduanya) dan perlengkapan input - output. Secara teknis, hanya ada 2 macam mikrokontroler. Pembagian ini didasarkan pada kompleksitas instruksi - instruksi yang dapat diterapkan pada mikrokontroler tersebut.

Menurut Syahwil (2013:60) “Arduino Uno adalah kit elektronik atau papan rangkaian elektronik open source yang di dalamnya terdapat komponen utama, yaitu sebuah chip mikrokontroler dengan jenis AVR dari perusahaan Atmel". Mikrokontroler itu sendiri adalah chip atau IC (Intergrated Circuit) yang bisa diprogram menggunakan komputer. Tujuan menanamkan program pada mikrokonroler adalah agar rangkaian elektronik dapat membaca input, memproses input tersebut dan kemudian menghasilkan output sesuai yang diinginkan. Jadi mikrokontroler bertugas sebagai 'otak' yang mengendalikan input, proses dan output sebuah rangakian elektronik.

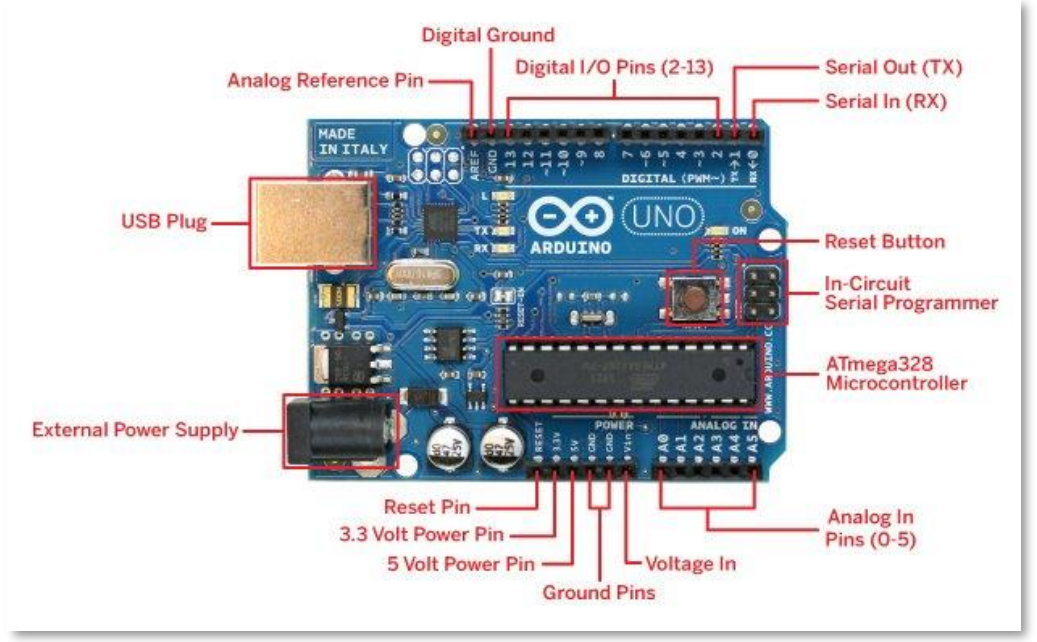

Gambar 1 Arduino

\subsection{Pulse Width Modulation (PWM)}

Pengontrolan dengan teknik Pulse Width Modulation (PWM) adalah sebuah cara memanipulasi lebar pulsa dalam perioda yang konstan untuk mendapatkan tegangan rata-rata yang berbeda (Syahrul 2014:603). Secara umum Pulse Width Modulation (PWM) adalah sebuah cara memanipulasi lebar sinyal yang dinyatakan dengan pulsa dalam suatu perioda, untuk mendapatkan tegangan rata-rata yang berbeda. Beberapa Contoh aplikasi PWM adalah pemodulasian data untuk telekomunikasi, pengontrolan daya atau tegangan yang masuk ke beban, regulator tegangan, audio effect dan penguatan, serta aplikasi-aplikasi lainnya. Aplikasi PWM berbasis mikrokontroler biasanya berupa, pengendalian kecepatan Motor DC, pengendalian Motor servo, dan juga pengaturan nyala kipas. 


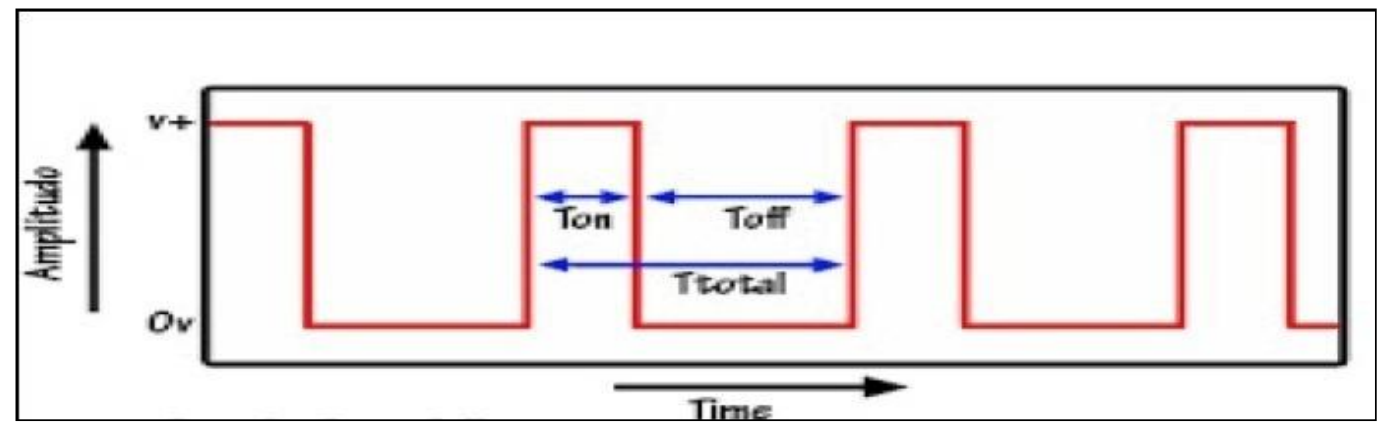

Gambar 2. Sinyal PWM

$$
\begin{aligned}
\text { Ttotal } & =\text { Ton }+ \text { Toff } \\
\mathrm{D} & =\frac{\text { Ton }}{\text { Ttotal }} \\
\text { Vout } & =\text { D } \mathrm{x} \text { Vin } \\
\text { Vout } & =\frac{\text { Ton }}{\text { Ttotal }} \times \text { Vin }
\end{aligned}
$$$$
\text { Ton = waktu pulsa "High" }
$$$$
\text { Toff = waktu pulsa "Low" }
$$$$
\mathrm{D}=\text { Duty cycle adalah lamanya }
$$$$
\text { pulsa high dalam satu periode }
$$

\section{PEMBAHASAN DAN HASIL}

Teknik Pulse Width Modulation (PWM) pada jagung berguna untuk mengatur cepat ataupun sedangnya putaran yang dikeluarkan oleh Motor DC. Cara kerja teknik PWM ini pada alat pemanggang jagung adalah saat sensor mendeteksi panas yang tinggi, maka PWM akan mengatur Motor DC agar putaran yang dikeluarkan oleh Motor DC cepat. Sebaliknya, jika sensor tidak mendeteksi adanya panas yang tinggi maka putaran Motor DC tersebut akan normal. Dalam hal ini yang melakukan pengaturan PWM ini adalah Arduino Uno berdasarkan informasi yang diterimanya melalui sensor.

1. Duty Cycle

Pada pemanggang jagung ini hanya memiliki 2 kondisi duty cycle yaitu $40 \%$ dan juga $100 \%$. Berikut akan diberikan gambaran dari duty cycle yang ada pada pemanggang jagung tersebut :

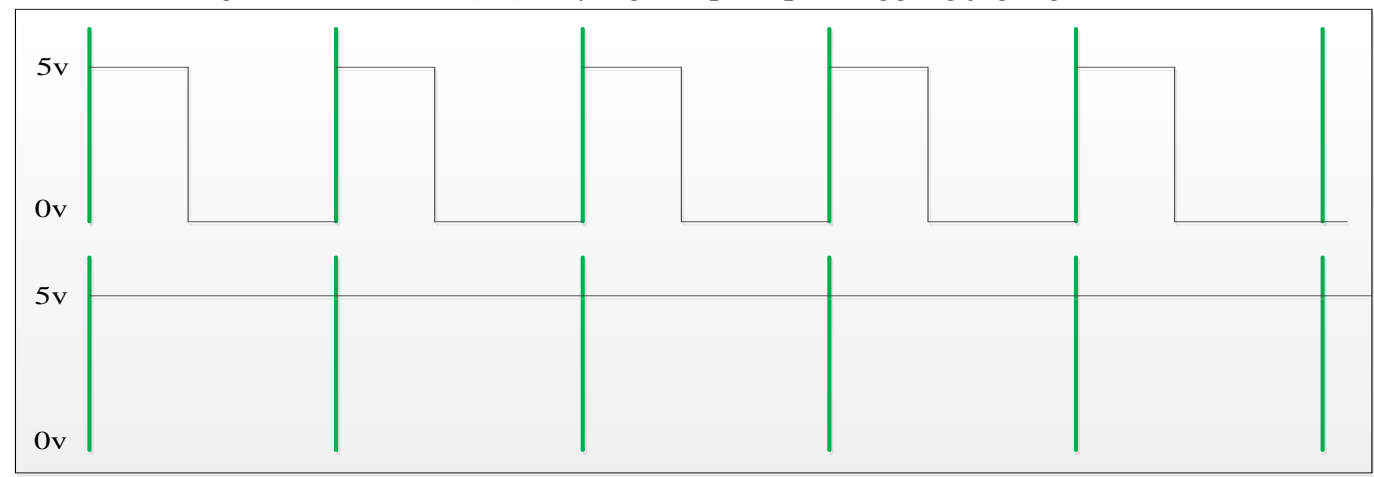

Gambar 3 Duty cycle $40 \%$ dan $100 \%$ pada Pemanggang Jagung

2. Nilai PWM

Nilai PWM yang terdapat pada pemanggang jagung akan dihitung berdasarkan duty cycle yang ada pada pemanggang jagung yaitu dan juga resolusi PWM yang akan dipakai yaitu 8 bit yang bernilai 0255 (256). Berikut adalah perhitungan nilai PWM yang ada pada pemanggang jagung:

a. $40 \%$ Duty cycle

$$
\begin{aligned}
\text { PWM } & =\text { Duty cycle } * \text { Resolusi PWM } \\
& =40 \% * 255 \\
& =102
\end{aligned}
$$

b. $100 \%$ Duty cycle

PWM = Duty cycle $*$ Resolusi PWM 


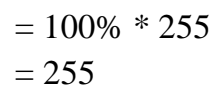

Perhitungan PWM tersebut digunakan untuk mengatur jumlah duty cycle yang akan dipakai Motor DC dan kipas.

3. Tegangan Output

Tegangan output ataupun tegangan yang akan diberikan pada Motor DC akan dihitung berdasarkan duty cycle yang ada pada pemanggang jagung dan juga jumlah sumber tegangan yang ada pada pemanggang jagung. Berikut adalah perhitungan tegangan yang akan diberikan pada Motor DC :

a. $40 \%$ Duty cycle

$=$ Duty cycle $*$ Vin

$=40 \% * 9 \mathrm{~V}$

$=3,6 \mathrm{~V}$

b. $100 \%$ Duty cycle

$=$ Duty cycle $*$ Vin

$=100 \% * 9 \mathrm{~V}$

$=9 \mathrm{~V}$

Jadi, dari perhitungan diatas dapat disimpulkan bahwa, jika sensor tidak mendeteksi panas yang tinggi, maka Motor DC akan mengeluarkan 1/4 putaran dari putaran maksimal Motor DC yaitu 40\% dan tegangan yang dikeluarkan untuk menghasilkan putaran tersebut adalah 3,6V. Jika sensor mendeteksi panas yang tinggi maka Motor DC akan mengeluarkan putaran maksimalnya yaitu $100 \%$ dan tegangan yang dikeluarkan untuk menghasilkan putaran tersebut adalah $9 \mathrm{~V}$.

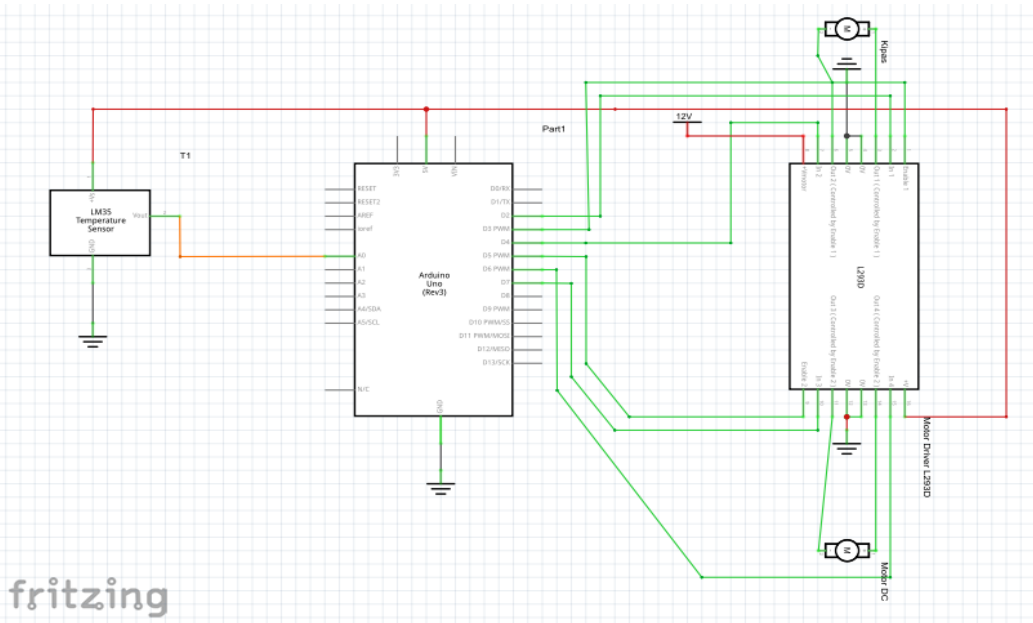

Gambar 3 Rangkaian Sistem

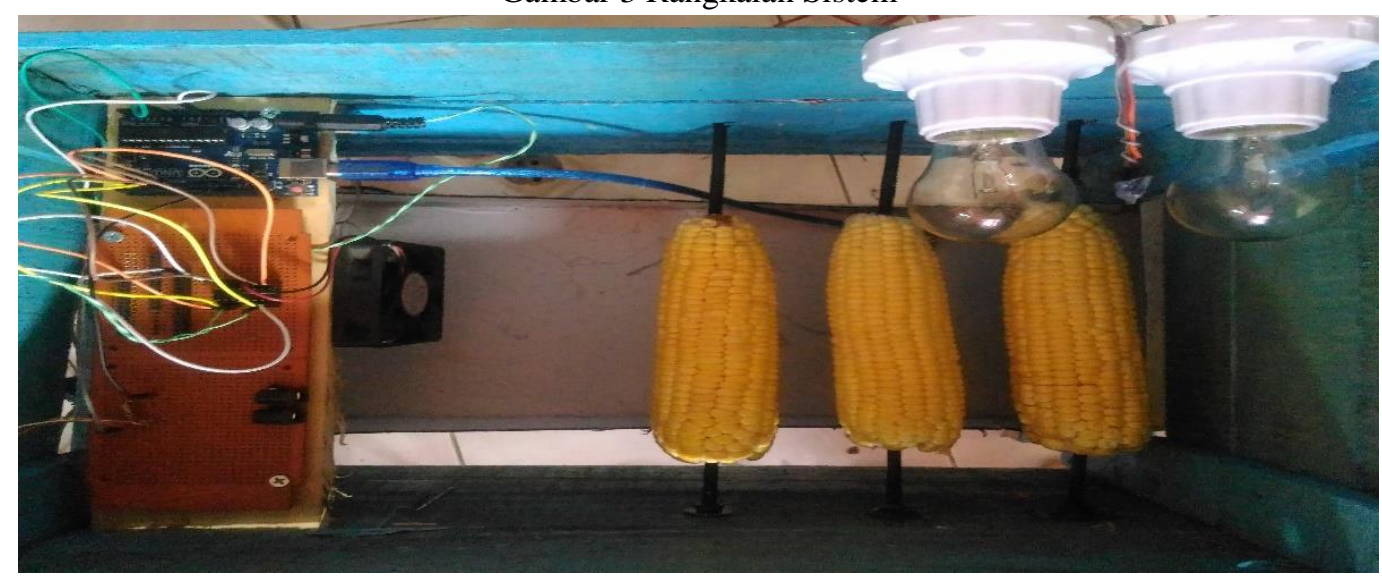

Gambar 4 Sistem Pembakar Jagung Otomatis 


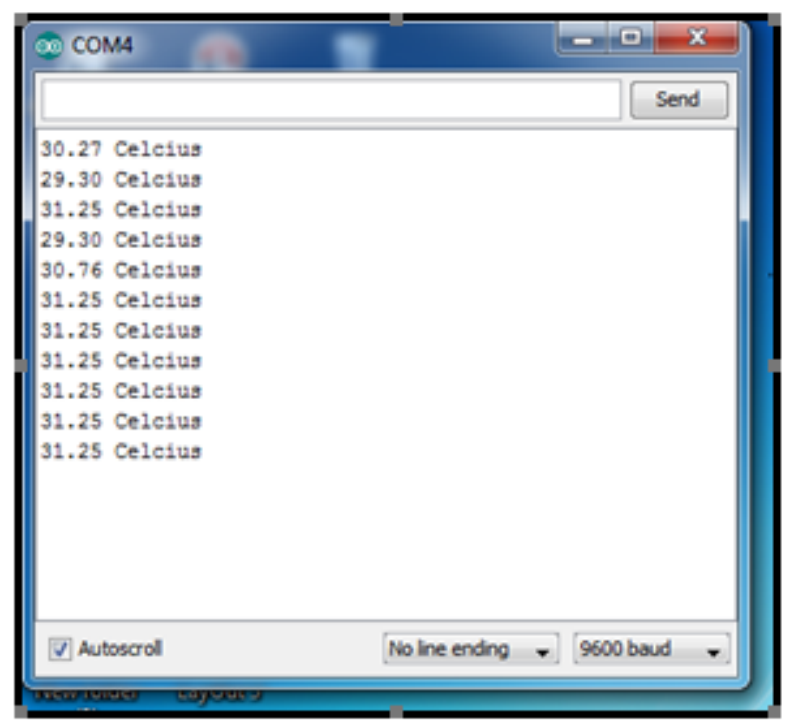

Gambar 5 Data Sensor LM35

\section{KESIMPULAN}

Adapun kesimpulan yang dapat diambil dari rancang bangun pemanggang jagung otomatis menggunakan teknik PWM (Pulse Width Modulation) berbasis mikrokontroler yaitu :

1. Cara merancang sistem pemanggang jagung otomatis berbasis mikrokontroler dengan menggunakan Motor DC sebagai penggerak dan Kipas sebagai penjaga suhu secara otomatis yang diperintah/dikendalikan oleh Mikrokontroler.

2. Cara menerapkan sensor LM35, sensor dihubungkan dengan mikrokontroler pada rangkaian, sensor mengirim nilai suhu panas arang kepada mikrokontroler, sehingga mikrokontroler mengirim nilai/duty cycle kepada motor DC dan Kipas.

3. Cara menerapkan teknik PWM (Pulse Width Modulation) dengan mengatur arus atau tegangan yang masuk pada Motor DC dan Kipas, sehingga Motor DC dan Kipas bergerak dengan kecepatan sedang ataupun maksimal.

\section{REFERENSI}

[1] Darmawan, A. H. A. (2016). Arduino Belajar Cepat Dan Pemrograman. Bandung. Informatika Bandung.

[2] Kadir, A. (2013). Panduan Praktis Mempelajari Aplikasi Mikrokontroler dan Pemrogramannya Menggunakan Arduino. Yogyakarta : ANDI.

[3] Nuchayo, S. (2012). Aplikasi Dan Teknik Pemrograman Mikrokontroler AVR Atmel. Yogyakarta : ANDI.

[4] Syahrul, (2014). Pemrograman Mikrokontroler AVR Bahasa Assembly dan C. Bandung : Informatika Bandung.

[5] Syahwil, M. (2013). Panduan Mudah Simulasi dan Praktik Mikrokontroler Arduino. Yogyakarta : ANDI.

[6] Reski, (2012). Perilaku Kadar Air Dan Warna Biji Jagung Perilaku Kadar Air Dan Warna Biji Jagung Menurut Waktu Panen Perilaku Kadar Air Dan Warna Biji Jagung. Ditemukenali 05 April 2017, dari http://repository.unhas.ac.id/handle/123456789/3662. 